\title{
The effect of lockdown on intentional and non- intentional injury during the COVID-19 pandemic in Cape Town, South Africa: A preliminary report
}

\author{
P H Navsaria, ${ }^{\mathbf{1}, 2}$ MB ChB, MMed (Surg), FCS, Cert Trauma Surgery, FACS; A J Nicol, ${ }^{\mathbf{1 , 2}}$ MB ChB, FCS, Cert Trauma Surg, PhD; \\ C D H Parry, ${ }^{3,4}$ BSocSc, BSc (Hon), MSc, MA, PhD; R Matzopoulos, ${ }^{2,5,6}$ BBusSci, MPhil, PhD; S Maqungo, ${ }^{2,7}$ MB ChB, FCOrtho, \\ MMed (Ortho); R Gaudin, ${ }^{1,7} \mathrm{MD}$ \\ ${ }^{1}$ Trauma Centre, University of Cape Town and Groote Schuur Hospital, Cape Town, South Africa \\ 2 Trauma Advocacy Group, University of Cape Town and Groote Schuur Hospital, Cape Town, South Africa \\ ${ }^{3}$ Alcohol, Tobacco and Other Drug Research Unit, South African Medical Research Council, Cape Town, South Africa \\ ${ }^{4}$ Department of Psychiatry, Stellenbosch University, Stellenbosch, South Africa \\ ${ }^{5}$ Burden of Disease Research Unit, South African Medical Research Council, Cape Town, South Africa \\ ${ }^{6}$ School of Public Health \& Family Medicine, University of Cape Town, Cape Town, South Africa \\ ${ }^{7}$ Orthopaedic Trauma Unit, Division of Orthopaedics, University of Cape Town and Groote Schuur Hospital, Cape Town, South Africa
}

Corresponding author: P H Navsaria (pradeep.navsaria@uct.ac.za)

Background. In response to the coronavirus pandemic, lockdown restrictions and a ban on alcohol sales were introduced in South Africa. Objectives. To investigate the impact of lockdown measures on the number of patients who visited a tertiary urban trauma centre. Methods. The period of investigation was from 1 February to 30 June 2020 and was segmented into three intervals: pre-lockdown (February and March 2020), hard lockdown (April and May 2020) and immediately post lockdown (June 2020). The electronic HECTIS health record registry was interrogated for the total number of patients that were seen per month. These were further categorised according to mechanism of injury (stab, gunshot, blunt assault and road traffic injuries). Penetrating (stab and gunshot) and blunt assault victims were collectively grouped as violent trauma.

Results. The mean total number of patients seen decreased by $53 \%$ during the hard lockdown period. There was a moderate reduction (15\%) in patients with gunshot injuries seen during the hard lockdown phase, but there was an $80 \%$ increase in the post-lockdown period. The proportion of patients injured in road traffic collisions pre lockdown, hard lockdown and immediate post lockdown was $16.4 \%$, $8.9 \%$ and $11.1 \%$, respectively. Patients injured in road traffic collisions decreased by $74 \%$ during the hard lockdown period and maintained a reduction of $32 \%$ during the immediate post-lockdown period. The mean total number of patients who visited the trauma unit returned to pre-lockdown levels in June.

Conclusion. There was an overall trend of reduced number of patients who visited the trauma unit during the hard lockdown period; however, these numbers returned to pre-lockdown levels during the immediate post-lockdown period. The number of road traffic injury admissions remained reduced during all three phases of lockdown, while the number of gunshot victims increased substantially during the post-lockdown period.

S Afr Med J 2021;111(2):110-113. https://doi.org/10.7196/SAMJ.2021.v111i2.15318

In keeping with the universal response to the coronavirus (SARSCoV-2) pandemic, lockdown measures were introduced in South Africa (SA). The SA government decreed five lockdown alert levels ranging from alert level 5, which entailed drastic measures to contain the spread of the virus to alert level 1, where reintroduction of normal activity was envisioned (Fig. 1). All non-essential activities were suspended. The lockdown included curfews, stay and work from home orders for non-essential workers, and restrictions on gatherings and public transport. Furthermore, the gazetted regulations stipulated an absolute ban on sales of alcohol and tobacco products. In the backdrop of this pandemic, there is the pre-existing quadruple burden of disease that plagues the SA people, aptly referred to as a cocktail of four colliding epidemics: maternal, newborn and child health; HIV/AIDS and tuberculosis (TB); non-communicable diseases; and violence and injury. Injuries are a major contributor to the burden of disease and interpersonal violence accounts for a greater share of the injury burden in SA than most other countries. ${ }^{[1]}$ The homicide rate is among the highest in the world, while road injuries are the third and fourth leading cause of deaths among men and women, respectively. ${ }^{[2]}$

There was a substantial decrease in trauma admissions countrywide and when the police minister, Mr Bheki Cele, was releasing the quarterly crime statistics covering the lockdown period (April - June), he remarked that 'a never-seen-before rosy picture of a peaceful South Africa experiencing a crime holiday. ${ }^{[3]}$ Over the period which coincided with lockdown, murder was down $35.8 \%$, attempted murder by $39.7 \%$, rape by $40.4 \%$ and assault with intent to cause grievous bodily harm by $41 \% .^{[3]}$ The number of drunk driving convictions went down by $85.5 \%$ and drug-related crime also dropped by $53 \%$ nationwide. ${ }^{[3]}$ Patients with preventable major trauma divert critical resources required to manage the COVID-19 crisis. We investigated the impact of lockdown measures on the number of patients with intentional and non-intentional injuries who visited a tertiary urban trauma centre in the Western Cape Province, SA. 


\section{Methods}

Groote Schuur Hospital (GSH) is the central referral hospital in the Cape Metro West Health District, which serves an estimated catchment area of 2300000 uninsured patients. It has 893 beds of which 50 beds (10 high care and 40 general surgery) are dedicated to trauma patients. The electronic HECTIS health record registry was implemented in the trauma centre at GSH in November 2019. HECTIS is a digital tracking healthcare platform used to monitor movements of patients through emergency units. Demographic data, standard triaging scores, mechanisms of injury, and management and disposal including international classification of disease codes are prospectively recorded in real-time by treating physicians and nursing staff.

Data from the HECTIS registry were supplied on request by the GSH Information Technology Department. Data extracted from the registry included the total number of patients seen per month. These were further categorised according to mechanism of injury: stab, gunshot, blunt assault and road traffic injuries. Penetrating (stab and gunshot) and blunt assault victims were collectively grouped as violent trauma. The period scrutinised was from 1 February 2020 to 30 June 2020 (5 months) and segmented into three periods: pre-lockdown (February and March 2020); hard lockdown (April and May 2020), which coincided with the restrictions on alcohol and tobacco sales; and post-lockdown (June 2020), which started at lockdown alert level 3 when people were allowed to return to work and there was a resumption of alcohol sales.

Ethical approval for the study was obtained from the University of Cape Town Human Research Ethics Committee (ref. no. HREC 434/2020).

\section{Results}

The average number of patients seen during the hard lockdown period (April - May

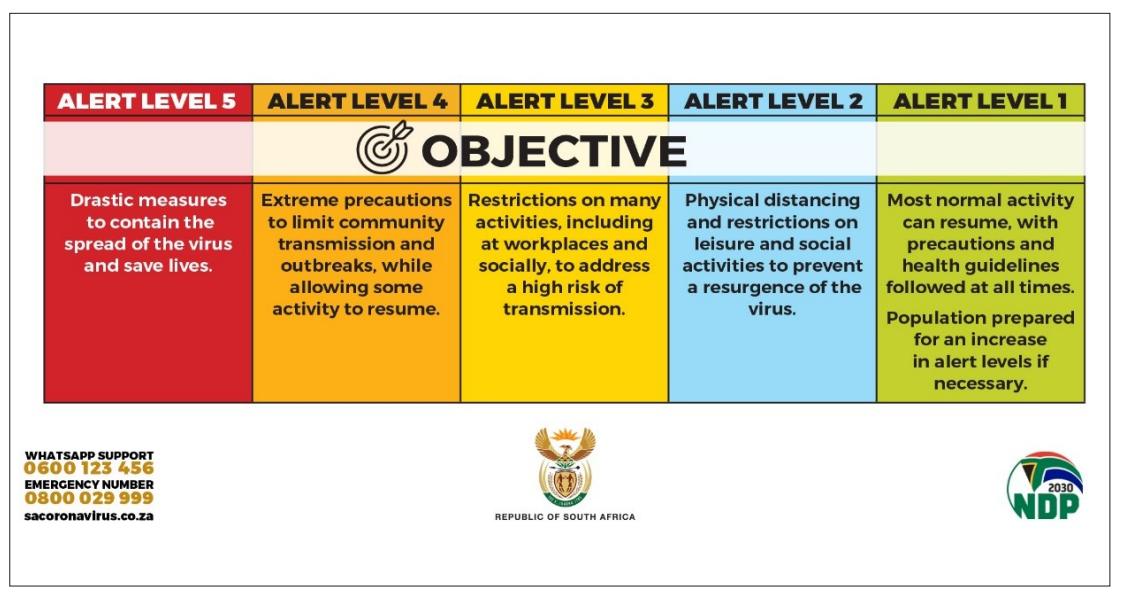

Fig. 1. Lockdown alert levels and objectives (source https://www.stateofthenation.gov.za/category/ infographics).
2020 , alert levels 5 and 4 ) decreased by $53 \%$. During the post-lockdown period (June 2020, alert level 3), the number of patients who visited the unit increased and returned to almost those numbers seen during the prelockdown period (Table 1). The proportion of patients who sustained violent trauma was unchanged over the three periods with pre-lockdown (37\%), lockdown (39\%) and post-lockdown (38\%). There was a slight decrease $(15 \%)$ in patients with gunshot wounds seen during the hard lockdown; however, there was a drastic increase $(80 \%)$ immediately post lockdown. The proportion of patients injured in road traffic collisions during pre-lockdown, hard lockdown and post-lockdown was $16.4 \%, 8.9 \%$ and $11.1 \%$, respectively. Patients injured in road traffic collisions decreased by $74 \%$ during the hard lockdown period and maintained a reduction of $32 \%$ during the immediate post-lockdown period (Table 1, Fig. 2).

\section{Discussion}

Our review of trauma presentations at GSH over the various phases of COVID19 lockdown in SA indicate a more than $50 \%$ drop in the average number of patients seen during the hard lockdown period (April - May 2020, alert levels 5 and 4). Despite a significant reduction in the number of interpersonal violence cases during the lockdown, the proportion of the trauma burden attributable to interpersonal violence remained unchanged. The total number of road traffic injuries decreased during the lockdown period. This can be attributed to both the lockdown and the ban on alcohol that reduced mobility and drunkenness, thereby reducing the number of road traffic crashes. Interpersonal

Table 1. Total patient visits for violent and road traffic injuries with percentage change during the 3 phases of lockdown

\begin{tabular}{|c|c|c|c|c|c|c|c|c|}
\hline & \multicolumn{8}{|c|}{ Groote Schuur Hospital Trauma Centre patient visits, 1 February - 30 June 2020} \\
\hline & \multicolumn{2}{|c|}{ Pre lockdown, $n$} & \multicolumn{2}{|c|}{ Lockdown, $n$} & \multirow{2}{*}{$\begin{array}{l}\text { Post lockdown, } \\
\text { June, } n\end{array}$} & \multirow{2}{*}{$\begin{array}{l}\text { Change pre v. } \\
\text { lockdown, } \%\end{array}$} & \multirow{2}{*}{$\begin{array}{l}\text { Change lockdown } \\
\text { v. post lockdown, \% }\end{array}$} & \multirow{2}{*}{$\begin{array}{l}\text { Change pre v. } \\
\text { post lockdown, \% }\end{array}$} \\
\hline & February & March & April & May & & & & \\
\hline Total & 710 & 618 & 322 & 306 & 666 & -53 & +112 & No change \\
\hline Mean & 664 & & 314 & & & & & \\
\hline \multicolumn{9}{|l|}{ Violent injuries } \\
\hline Gunshot & 45 & 34 & 37 & 30 & 73 & -15 & +115 & +83 \\
\hline Mean & 40 & & 34 & & & & & \\
\hline Stab & 95 & 80 & 34 & 31 & 74 & -61 & +124 & -16 \\
\hline Mean & 88 & & 33 & & & & & \\
\hline Blunt & 121 & 109 & 55 & 52 & 97 & -53 & +80 & -16 \\
\hline Mean & 115 & & 54 & & & & & \\
\hline Violent trauma, mean & 243 & & 121 & & 251 & -50 & +107 & +3 \\
\hline \multicolumn{9}{|l|}{ Road traffic injury } \\
\hline Total & 118 & 100 & 29 & 27 & 74 & -74 & +164 & -32 \\
\hline Mean & 109 & & 8 & & & & & \\
\hline
\end{tabular}




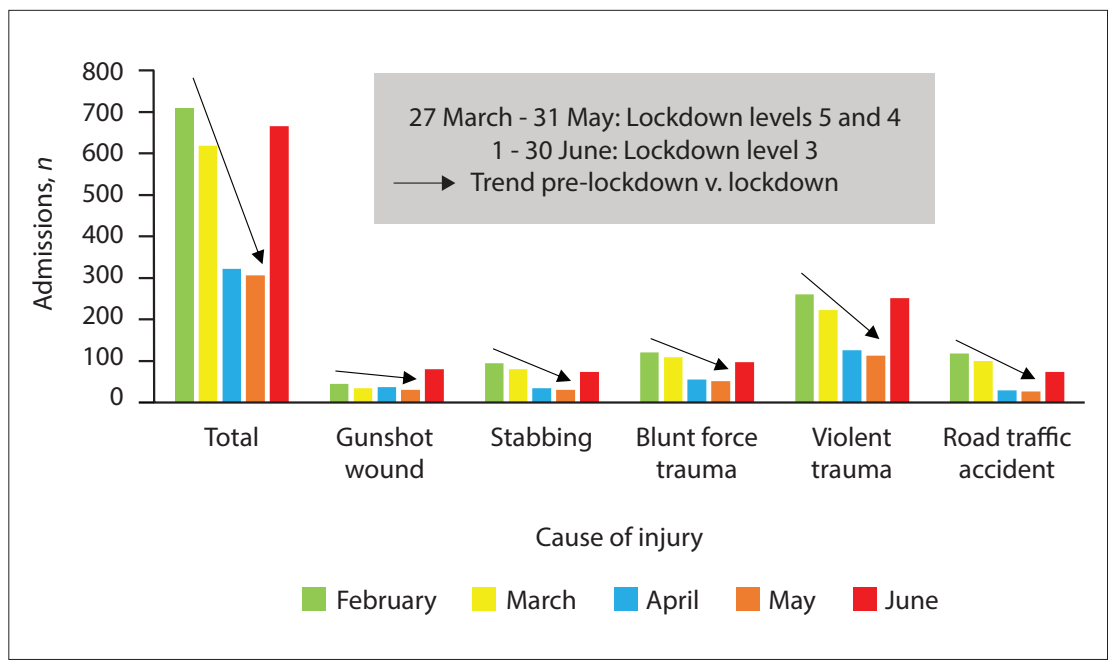

Fig. 2. Admissions to the Groote Schuur Hospital Trauma Centre, 1 February - 30 June 2020.

violence was expected to be reduced due to restricted social interactions in public space; however, this was offset by increased social interactions in the domestic setting. This trend demonstrates that a lot of violence is taking place at home and that people are not safe in their homes.

Internationally, there have been reports of a reduction in trauma presentations to emergency units as a result of lockdown measures. There was a reported $50 \%$ reduction in orthopaedic trauma referrals to a central London trauma unit, ${ }^{[4]}$ a $75 \%$ reduction in trauma presentations to a level 1 trauma centre in Barcelona ${ }^{[5]}$ and $43 \%$ reduction in all injury-related admissions in New Zealand. ${ }^{[6]}$ The reduction in trauma numbers is thought to be due to lower risks of workplace and traffic collisions, combined with a fear of attending hospitals. It is interesting to note that none of the three countries mentioned above implemented a ban on alcohol sales. However, there are major demographic and aetiological differences in the trauma presentations in these countries when compared with SA. Most injuries in the UK, Spain and New Zealand are caused by road traffic collisions and falls. Furthermore, the patients tend to be older (in their 50s), with a much higher proportion of female patients (52\% in Spain and 50\% in the UK). These countries do not have high numbers of interpersonal violence and the overall trauma numbers are low. The striking difference in the SA context is the large number of victims of interpersonal violence, a majority (90\%) of whom are young men in their 20s. ${ }^{[1]} \mathrm{A}$ major barrier to decreasing intentional injury mortality has been poor adherence to gun control with increased firearm availability and relaxation of alcohol access controls.

The homicide rate in SA is among the highest in the world. ${ }^{[7]}$ There has been a year-on-year increase in the number of homicides in men, and the rate of homicides due to guns has doubled from 17 to 35/100 000 people between 2010 and 2018. ${ }^{[2,8]}$ Firearmrelated homicide was the second leading cause of death after HIV/AIDS in the Western Cape Province in people aged 15 - 44 years of age. Homicide and road injuries are a leading cause of premature mortality and accounted for $7.3 \%$ and $4.6 \%$ of the years of life lost in 2012, respectively. ${ }^{[2]}$ Half of the homicide victims tested positive for alcohol and $45 \%$ of them had blood alcohol concentrations higher than the legal driving limit $(0.05 \mathrm{~g} / 100 \mathrm{~mL}) .{ }^{[8]}$ Researchers have highlighted a need for reliable data, and making gunshot injuries notifiable in the trauma unit would certainly assist in targeting prevention efforts. ${ }^{[9]}$

The absolute number of road injury deaths increased slightly between 2012 and 2018, but the age-standardised road injury mortality rates have remained fairly constant. ${ }^{[8]}$ There has been an increase in passenger deaths as well as a high number of pedestrian deaths.

Alcohol is a prominent risk factor for the high rates of injury. The harmful use of alcohol causes $\sim 3$ million (5.3\%) deaths per year worldwide. ${ }^{[10,11]}$ In people aged 20 - 39 years, $\sim 13.5 \%$ of the total deaths are attributed to alcohol. In fact, alcohol accounted for a considerably higher percentage of injuries in SA in 2000, with 63\% of alcohol-related disability adjusted life years compared with the rest of the world $(37 \%) .^{[1,10]}$ These statistics are reflective of the pattern of drinking rather than overall per capita consumption, which is more strongly associated with chronic conditions. SA has a moderate number of drinkers per capita ( $31 \%$ of the population), but the drinking pattern is characterised by very high levels of heavy episodic (binge) drinking (59\% of drinkers monthly). ${ }^{[10]}$ Several studies have highlighted the prominent role of alcohol as a risk factor for fatal and non-fatal trauma during weekends in the Western Cape Province. ${ }^{[6,10]}$ It has been estimated that $48 \%$ of trauma cases were alcoholrelated in our trauma unit in 2012. ${ }^{[12]}$ This mirrors the findings of a study undertaken at the same hospital between October 2010 and September 2011, where 45.3\% of trauma patients were clinically assessed as being under the influence of alcohol. ${ }^{[13]}$ Past research conducted in public hospital trauma units in cities (Cape Town, Port Elizabeth and Durban) over an idealised week in three years $(1999,2000,2001)$ reported that between $35.8 \%$ and $78.9 \%$ of patients tested positive for alcohol using a breath alcohol analyser. ${ }^{[14]}$

The data presented in this study clearly demonstrate that the easing of stricter lockdown restrictions resulted in an increase in trauma presentations. This coincided with the unbanning of alcohol sales and the relaxation on restrictions on movement. The number of patient visits due to road traffic injuries decreased by $74 \%$ and $32 \%$ during the hard lockdown and post-lockdown period, respectively. This sustained reduction can be explained by the significant drop in traffic counts for the N1, the N2, a section of the N7 and M5 freeways during a weekday since the start of the lockdown. However, the volumes increased significantly in May 2020 from $\sim 20 \%$ to $40 \%$, and the traffic volumes increased further to about $65 \%$ of the normal weekday levels as more people returned to work with the easing of the regulations in June 2020. ${ }^{[15]}$

What caused the trauma rebound effect, particularly the $107 \%$ increase in violent assaults and in particular, gunshots is unclear. Although the misuse of firearms is necessary for the occurrence of firearm violence, there are other contributing factors beyond simply firearms themselves that might also be modified to prevent firearm violence. Alcohol is one such key modifiable factor. A recent systematic review with meta-analysis (1975 - 2014) explored the role of alcohol and firearm violence. A large group of studies showed that over one-third of firearm violence decedents had acutely consumed alcohol and over a quarter had heavily consumed alcohol prior to their deaths. ${ }^{[16]}$ A small group of studies investigated the intersection of alcohol, firearm laws, alcohol outlets and firearm violence. One of these controlled studies found that off-premise outlets selling takeout alcohol were significantly associated with 
firearm assault. ${ }^{[17]}$ Policies that rezone off-premise alcohol outlets, prescribe blood alcohol levels, enhance penalties for carrying or using firearms while intoxicated and considering prior drunk driving convictions as a more precise criterion for disqualifying persons from the purchase or possession of firearms deserve further study. ${ }^{[18]}$

A ban on alcohol sales results in unemployment, which is a major factor in promoting violent behaviour. ${ }^{[18]}$ This results in a difficult balancing act of lives v. livelihood. When alcohol sales resume, we need to develop very strict regulations based on interventions that have been proven to reduce alcohol abuse. There is a need for a better regulatory environment for alcohol to minimise the negative health effects and social consequences. A 10-point plan has been suggested which includes, among others, reducing the number of alcohol sales days to three per week, enforcing a maximum blood alcohol concentration level for drivers of $0.02 \mathrm{~g} / 100 \mathrm{~mL}$, mandatory testing for blood alcohol after motor vehicle collisions, and alcohol-related trauma should be a notifiable condition at trauma units. ${ }^{[19]}$

During health emergencies such as the current COVID-19 pandemic, violence against women increased. Violence against women is highly prevalent and intimate partner violence is the most common form of violence. ${ }^{[20]}$ While data are scarce, reports from across the world including China, ${ }^{[2]}$ the United Kingdom, the United States of America, and other countries show a significant increase in domestic violence cases related to the COVID-19 pandemic. Reports from other countries suggest a reduction in survivors who seek services due to a combination of lockdown measures and a fear of infection at healthcare centres. Similarly, cases of abuse of women and children have also dramatically increased in SA since alert level 3 took effect on 1 June 2020. ${ }^{[22]}$ We were not able to show this trend in our unit because the registry did not make provisions for recording gender-based violence. This has since been rectified and included in the Hectis registry.

\section{Study limitations}

The month of March included the period of 'lockdown light' from 18 to 26 March, where there were limits on the number of hours and days in a week of off-consumption sales, and on-consumption sales were only permitted until $6 \mathrm{pm}$ and no more than 50 patrons were allowed in an on-consumption outlet at one time. It also included the period 27 - 31 March when no sales of alcohol were permitted. This might have deflated the trauma numbers for the pre lockdown period. We have had to infer the effect of the alcohol ban and the lockdown due to the strong correlation between alcohol and social interactions as a risk for injuries. Our findings pertain to one large teaching hospital in the legislative capital of the county and might not necessarily directly reflect trauma units in other parts of the country.

\section{Conclusion}

SA imposed a two-month long hard lockdown that was effective at slowing the spread of the virus. The current study findings show that interventions like a ban on liquor sales together with restrictions on movement can have a dramatic and rapid impact on the number of trauma presentations in SA and that such an impact is rapidly reversed when such interventions are lifted. However, the impact is not the same on all types of trauma injuries and it appeared to be greatest for violence-related trauma. While a ban of liquor sales is not a viable option, other regulatory inventions need to be explored which might have an impact on the culture of heavy drinking in the country. The reduction in violent crime was probably not only due to the alcohol ban, but also to people staying in their homes and high-visibility policing, including the presence of the army. There is certainly a need for more reliable data, and making gunshot injuries and alcohol-related trauma notifiable and making alcohol testing in all emergency units mandatory would certainly assist in future prevention efforts.

\section{Declaration. None.}

\section{Acknowledgements. None.}

Author contributions. PHN and AN conceptualised the study, PHN and RG collected the data and PHN, CP and RM analysed the data. PHN wrote the manuscript and CP, RM, SM and RG revised the manuscript. All authors approved the manuscript for publication.

Funding. We gratefully acknowledge funding from the South African Medical Research Council for covering the salaries of CP and RM and facilitating their contribution in the preparation of this manuscript.

Conflicts of interest. None.

1. GBD 2013 mortality and causes of death collaborators. Global, regional, and national age-sex specific all-cause and cause-specific mortality for 240 causes of death, 1990-2013: A systematic analysis for the Global Burden of Disease Study 2013. Lancet 2015;385(9963):117-171. https://doi:10.1016/S01406736(14)61682-2

2. Matzopoulos R, Prinsloo M, Pillay-van Wyk V, et al. Injury-related mortality in South Africa: Matzopoulos R, Prinsloo M, Pillay-van Wyk V, et al. Injury-related mortality in South Africa:
A retrospective descriptive study of post-mortem investigations. Bull World Health Organ 2015;93(5):303-313. https://doi:10.2471/BLT.14.145771

3. Waterworth T, Chemaly F. 'Crime holiday' in lockdown as Cele guns for booze. https://www.iol.co.za/ ios/news/crime-holiday-in-lockdown-as-cele-guns-for-booze-5009670a-11f4-4fda-9e4f-e372baa8e652 (accessed 15 August 2020)

4. Park C, Sugand K, Nathwani D, Bhattacharya R, Sarraf KM. Impact of the COVID-19 pandemic on orthopedic trauma workload in a London level 1 trauma centre: The 'golden month.' Acta Orthop 2020;1-6. https://doi:10.1080/17453674.2020.1783621

5. Nuñez JH, Sallent A, Lakhani K, et al. Impact of the COVID-19 pandemic on an emergency traumatology service: Experience at a tertiary trauma centre in Spain. Injury 2020;51(7):1414-1418. https:// doi:10.1016/j.injury.2020.05.016

6. Christey G, Amey J, Campbell A, Smith A. Variation in volumes and characteristics of trauma patients admitted to a level one trauma centre during national level 4 lockdown for COVID-19 in New Zealand. N Z Med J 2020:133(1513):81-88.

7. Pillay-van Wyk V, Msemburi W, Laubscher R, et al. Mortality trends and differentials in South Africa 7. Pillay-van Wyk V, Msemburi W, Laubscher R, et al. Mortality trends and differentials in South Africa
from 1997 to 2012: Second national burden of disease study. Lancet Glob Health 2016;4(9):e642-e653.

8. Matzopoulos R, Simonetti J, Prinsloo M, et al. A retrospective time trend study of firearm and nonfirearm homicide in Cape Town from 1994 to 2013. S Afr Med J 2018;108(3):197-204. https:// doi:10.7196/SAMJ.2018.v108i3.12756

9. Matzopoulos R, Prinsloo M, Bradshaw D, Abrahams N. Reducing homicide through policy interventions: The case of gun control. S Afr Med J 2019;109(11b):63-68. https://doi:10.7196/SAMJ.2019. v109i11b.14256

10. Schneider M, Norman R, Parry C, Bradshaw D, Plüddemann A. Estimating the burden of disease attributable to alcohol use in South Africa in 2000. S Afr Med J 2007;97(8):664-672.

11. World Health Organization. Global Status Report on Alcohol and Health. Geneva: WHO, 2018. https:// www.who.int/substance_abuse/publications/global_alcohol_report/gsr_2018/en/ (accessed 4 August 2020).

12. Nicol AJ, Sorsdahl K, Hoffman R, et al. Violence and substance use at a Cape Town trauma centre. Presented at the Safety and Violence Initiative (SAVI) of the University of Cape Town inaugural conference. November 2013.

13. Schuurman N, Cinnamon J, Walker BB, et al. Intentional injury and violence in Cape Town, South Africa: An epidemiological analysis of trauma admissions data. Glob Health Action 2015;8:27016. https:// doi:10.3402/gha.v8.27016

14. Plüddemann A, Parry C, Donson H, Sukhai A. Alcohol use and trauma in Cape Town, Durban and Port Elizabeth, South Africa: 1999 - 2001. Inj Control Saf Promot 2004;11(4):265-267. https://doi:10.1080/1 56609704/233/289599

15. City of Cape Town. Easing traffic congestion beyond COVID-19. City of Cape Town. http://www. capetown.gov.za/Media-and-news/Easing\%20traffic\%20congestion\%20beyond\%20COVID-19 (accessed 4 August 2020).

16. Branas CC, Han S, Wiebe DJ. Alcohol use and firearm violence. Epidemiol Rev 2016;38(1):32-45. https:// doi.org/10.1093/epirev/mxv010

17. Branas CC, Elliott MR, Richmond TS, Culhane DP, Wiebe DJ. Alcohol consumption, alcohol outlets, and the risk of being assaulted with a gun. Alcohol Clin Exp Res 2009;33(5):906-915. https://doi:10.1111/ j.1530-0277.2009.00912.c

18. Fergusson DM, McLeod GF, Horwood LJ. Unemployment and psychosocial outcomes to age 30: A fixed. Fergusson DM, McLeod GF, Horwood LJ. Unemployment and psychosocial outcomes to age 30: A fixed-
effects regression analysis. Aust N Z J Psych 2014;48(8):735-742. https://doi:10.1177/0004867414525840

19. Parry C, Gray G, Maker A, Smithers M. Charting a healthier way forward for alcohol in SA, now and into Parry C, Gray G, Maker A, Smithers M. Charting a healthier way forward for alcohol in SA, now and into
the future. https://www.dailymaverick.co.za/article/2020-07-27-charting-a-healthier-way-forward-foralcohol-in-sa-now-and-into-the-future/\#gsc.tab $=0$ (accessed 04 August 2020).

20. Moreira DN, Pinto da Costa M. The impact of the COVID-19 pandemic in the precipitation of intimate partner violence. Int J Law Psychiatry 2020;71:101606. https://doi.org/10.1016/j.ijlp.2020.101606

21. World Health Organisation. COVID-19 and violence against women: What the health sector/system can do? Geneva: WHO, 2020. https://apps.who.int/iris/bitstream/handle/10665/331699/WHO-SRH-20.04eng.pdf (accessed 15 August 2020).

22. Ellis E. Gender-based violence is South Africa's second pandemic says Ramaphosa. https://www. dailymaverick.co.za/article/2020-06-18-gender-based-violence-is-south-africas-second-pandemic-saysramaphosa/ (accessed 5 August 2020).

Accepted 18 November 2020 